\title{
DIREITO, PATRIMÔNIO CULTURAL URBANO E ATIVIDADE TURÍSTICA LAW, URBAN HERITAGE AND TOURIST ACTIVITY
}

\author{
Fernando Condesso ${ }^{1}$
}

\section{Resumo:}

A cidade é fonte de memória histórica e portanto de conhecimento e de fomento de cultura territorial e de turismo urbano. Este visa o conhecimento da cidade em si, com o seu património histórico ou contemporâneo, e a atividade cultural dos seus habitantes. A vida das cidades, numa perspetiva cultural e turística, assenta tanto no património legado como numa coerente contínua criação em todos os domínios, que defendam o carácter mas não deixem de imprimir vida à cidade.Ora, uma cidade que pretenda desenvolver uma atividade turística centrada no elemento cultural não pode prescindir de especiais preocupações no âmbito normativo e de políticas públicas implicando fundamentalmente intervenção protetivas e projetivas-promotoras no e sobre o meio urbano, desde operações de criação, proteção e recuperação a outras de proteção do património militar e, sendo o caso, no património portuário, em geral com reabilitação de locais e edifícios, afirmação de arte pública e promoção da imagem global da cidade. Mais importante do que construir ou demolir é manter e reconstruir, numa linha de reabilitação dos espaços e edifícios tradicionais, atirando para áreas novas, de natural expansão, os novos estilos arquitetónicos e materiais de construção.

Palavras-chave: cidade - cultura - patrimônio - turismo - reabilitação.

\section{Abstract:}

The town is a source of historical memory and therefore of knowledge and promotion of territorial culture and urban tourism. This aims knowledge of the city itself, with its historic or contemporary heritage and cultural activity of its inhabitants. The life of cities, in a cultural and tourist perspective, is based both on legacy heritage as a continuous coherent creation in all fields, which defend the character but do not forget to give life to the city. a city wishing to develop a focused tourism in cultural element can not do without special concerns in the regulatory framework and policy, implying fundamentally protective intervention and projective-promoters in and on the urban environment, from creation operations, protection and recovery to other protection of military assets and, where applicable, the port heritage, usually with rehabilitation of sites and buildings, affirmation public art and promote the global image of the city. More important than building or demolish and rebuild is to maintain in terms of rehabilitation of traditional buildings and spaces, moving into new areas of natural expansion, new architectural styles and building materials.

Keywords: city - culture - heritage - tourism - rehabilitation.

\footnotetext{
${ }^{1}$ Catedrático de direito administrativo da Universidade de Lisboa, Doutor em Direito e Doutor em Planeamento Territorial
} 


\section{CIDADE, CULTURA E TURISMO}

A cidade, fonte de memória histórica (no plano físico, costumes e tradições), e de criação permanente de cultura territorial, exerce um crescente estímulo turístico ${ }^{2}$, motor da prosperidade na economia europeia (valor acrescentado, emprego $)^{3-4}$.

Ele interfere com o desenvolvimento equilibrado e harmonioso das cidades e dos territórios.

O movimento turístico dá-lhe à cidade uma imagem atrativa, que facilita o seu crescimento económico e a sua coesão social ${ }^{5}$. E, ao privilegiar as motivações culturais, liberta-a, em parte, de restrições geográficas e sazonais ${ }^{6}$. Mas, para se criarem projetos concretos, são necessárias políticas e planos de desenvolvimento local de turismo e de cultura, de políticas promocionais e do enquadramento jurídico que os favoreça.

A conjugação do urbano e do cultural num conceito misto, referido ao fenómeno turístico, aparece em termos imprecisos. Aliás, mantém-se ainda a querela sobre a definição e objeto do urbanismo ${ }^{7-8-9}$.

\footnotetext{
${ }^{2}$ Europe's Environment: The Dobris Assessment. European Environment Agency (State of the environment report n.1), May 20, 1995, http://www.eea.europa.eu/publications.Emgeral, vide em geral CONDESSO, F.Turismo urbano e rural e cutrimónio cultural. http://condesso2011.no.comunidades.net/index.php?pagina=1773640575; HAYWOOD, K.M -«Identifying and Responding to Challenges Posed by Urban Tourism». Tourism Recreation Research 17, n. 2, p.9-23, 1992; ASHWORTH, G.J -«Urban Tourism: An Imbalance in Attention». C.P. Cooper- Progress in Tourism, Recreation and Hospitality Management. Londres, Belhaven Press, p. 33-54; VANDERMEY, A. -«Assessing The Importance of Urban Tourism». Tourism Management 5, n. 2, 1984, p. 123-35.

${ }^{3}$ CUNHA, L. - "Efeitos económicos do Turismo". Economia e Política do Turismo. Lisboa: McGRAW-HILL, p.225291; VVAA -Annais of Tourism Research: A social Science Journal. Vol.12, n.o 4, Pergamon Press, 1985; Vol.18, n.. 2, Pergamon Press, 1991; VVAA -The Tourist Review, n. 2/93, International Association of Scientific Experts in Tourism, 1993.

4 No século XIX, v.g., STENDHAL, relato de viagem "Roma, Nápoles e Florença",1827, http://www.estacaoliberdade.com.br/autores/stendhal.htm.

${ }^{5}$ Vide, POTIER, F. -Le Turisme Urbain. Les Pratiques des Français. Paris: INRETS, 1996.

${ }^{6}$ A concentração temporal do turismo de massas é um fator de risco ambiental. CONDESSO, F.-"O urbanismo ambiental Turístico", Direito do Ambiente. Almedina, 2001, p.1184 e ss.

${ }^{7}$ Entre um conceito amplo, ao jeito das country and town planning acts, e um restrito, referente apenas à cidade (v.g., em Portugal, debate jurídico sobre a proposta governamental da Lei de Bases do Ordenamento do Território): Revista Jurídica, no 22, 1998, Nova Série, Ordenamento do Território, número temático, Associação Académica da Faculdade de Direito de Lisboa, p. 22; CONDESSO, F. -Direito do Urbanismo: Noções Fundamentais. Lisboa: Quid Juris?1999.p.32 e ss.

${ }^{8}$ Nem existe uma distinção pacífica entre cidade ou aglomerado urbano e aldeia ou aglomerado rural, não parecendo dever bastar à qualificação de cidade apenas a referência a um número mínimo de habitantes. Exigem-se outras referências infraestruturais e culturais: CONDESSO, F., idem.

${ }^{9}$ Sobre urbanismo, aglomerado urbano, turismo urbano, ambiente urbano, património cultural, etc.: CONDESSO, F. - Direito do Ambiente. Coimbra: Akmedina, 2014; Direito do Urbanismo.(...). Lisboa: Quid Juris, 1999; -Direito do Ambiente. Coimbra: Almedina, 2001; -Ordenamento do Território (...). Lisboa: ISCSP, 2005; -El desarrollo armónico de la Península Ibérica. (...). Barcelona: Erasmus Ediciones, 2010; -Turismo (...), oc.
} 
No que se refere ao conceito de cultura, a Declaração do México saída da Reunião Mundial do Turismo, de $1982^{10}$, define-a em termos amplos, englobando, além das artes e das letras, os modos de vida, os valores fundamentais do ser humano, os sistemas de valores, as tradições e as crenças.

Nesta linha, por património cultural deve compreender-se o património histórico situado (vestígios arqueológicos, castelos, edifícios religiosos, parques e jardins), museus ${ }^{11}$, eventos culturais (festivais de música, dança, óperas, arte dramática, folclore, cinema, manifestações culturais conjugadas com festas tradicionais ou comemorações -concertos, exposições, espetáculos ao vivo, colóquios científicos ou profissionais-, feiras internacionais (avaliação do progresso da ciência e da tecnologia ${ }^{12-13}$ ) e exposições universais ${ }^{14}$, peregrinações e cerimónias religiosas; e o turismo económico, industrial ou técnico (processos de fabrico e organização do trabalho: fontes de energia -eletricidade, petróleo-, produtos de consumo alimentar ou industrial ou transportes) ${ }^{15-16}$.

Em geral, o produto turístico cultural é constituído pela síntese de vários elementos distintos, desde os propriamente culturais, vivenciais (meios de transporte ${ }^{17}$; alojamento; e áreas de restauração) e centros de interesse e envolventes ambientais (na linha do programa europeu das «cidades sustentáveis»).

A vida das cidades, neste âmbito cultural, repousa não só sobre um património legado por uma longa história como numa contínua, ativa e criativa evolução em todos os domínios ${ }^{18}$.

Desde o da perceção e utilização dos monumentos e outros "documentos" históricos ${ }^{19}$, museus de grande valor ou centros antigos, e de edifícios modernos com arquitetura de qualidade

${ }^{10}$ OMT -Declaration du México: Reunion Mondiale du Tourism, julho a agosto de 1982; 17. diretriz geral, alíneas g e h, p.7.

11 Definidos em 1974, pelo Conselho Internacional dos Museus: http://www.icomportugal.org/pagina,129,129.aspx.

${ }^{12}$ V.g., Em Lisboa, a última exposição universal do século XX, sobre o tema dos Oceanos.

${ }^{13}$ Organizadas periodicamente desde 1852.

${ }^{14}$ Já em 1900, 51 milhões de visitantes em Paris.

${ }^{15}$ Vide, Premiéres Assises du Turism Urbain, Reines, 1990.

${ }^{16}$ Hoje, tende a orientar-se o património histórico edificado para a vida social (exposições temporárias, encontros, centros de estudo) e para a atividade económica (venda de especialidades locais ou de produtos artesanais).Por influência, v.g., de PROSPER MÉRIMÉE, em França, irmãos GRIMM, na Alemanha, JONH RUSKIN, na Inglaterra. E, depois, com a criação de instituições especializadas (National Trust, em Inglaterra, Caisse Nationale de Monuments Historiques, em França, e serviços ministeriais, noutros países). Mais recentemente, graças à ação de associações como «Europa Nostra». Em 1974, The World Heritage Convention previu classificar como «património mundial» os mais belos locais e monumentos, com base no Relatório de peritos da International Council on Monuments and Sites. Vide http://whc.unesco.org/en/list/stat.

${ }_{17}$ POTIER, F.; BIEBER, A. «Transport and the Development of Tiurism: Some European Long-Term Scenarios». Transport and Communications: Innovation in Europe, Londres. Belhaven Press, 1993.

${ }^{18}$ OCDE -“Politique du Turisme et Tourisme International dans les Pays de I'OCDE, 1992-1993".

${ }^{19}$ OMT -“Tendences des Marchés Touristiques", Europe, 1997; - “Evolution du tourisme a l'échelle mondiale et en Europe.1980/1992". 
(cidades de arte), à organização de espetáculos, viagens com temas guiados, circuitos de rotas, circuitos de visita, festivais, dança, óperas, arte dramática, folclore e cinema, acontecimentos excecionais ou periódicos, (cidades de festas e festivais ${ }^{20}$ ); encontros políticos, empresariais, científicos e culturais em geral, e salões, exposições, cursos ou grandes reuniões (cidades de congressos e universitárias); onde as pessoas podem tratar da sua saúde e repousar, muitas vezes, complementado com climas, fontes termais ou praias, muitas vezes como recurso exterior ou lateral (cidades termais e com estâncias de férias e ócio, de mar e montanha), casos que exigem redobrados cuidados e normações jurídicas no plano ambiental (trânsito, ruído, poluição do ar ou obras, ou seja, cidades ambientalmente sãs e com qualidade de vida ${ }^{21}$ ) e operações de embelezamento em projetos de intervenção integrada.

Este turismo urbano exige um ambiente atrativo, que implica fortemente a defesa do património cultural como um desafio político, económico e cultural fundamental.

As cidades atrativas ${ }^{22}$, de turismo urbano centram-se sobretudo no turismo cultural ${ }^{23}{ }^{24}{ }^{25}$.

O turismo urbano visa o conhecimento da cidade em si, seu charme, seu património histórico ou contemporâneo e dos resultados da atividade cultural dos seus habitantes.

Em geral, tem-se legislado em termos protetivos e projetivos, ou seja, também de promoção de operações de reabilitação, em ordem a fazer reviver os bairros antigos, sendo aliás mais decisivo manter ou reconstruir do que demolir e construir, fomentando-se a reabilitação da arquitetura tradicional da zona e colocando nas áreas de expansão a nova arquitetura (v.g., Viena).

Os parques e jardins, mesmo que anexos a habitações ou palácios, aparecem como obras de arte, valorizando as belas construções ou ilustrando um estilo ou uma época.

Quanto ao património histórico situado, a sua conservação cabe às políticas públicas e ao direito urbanístico, patrimonial e ambiental.

As construções modernas, unidades fabris, edifícios públicos, edifícios que marquem o sucesso de uma técnica ou que traduzam uma nova conceção de organização social, sempre que tenham de

\footnotetext{
${ }^{20} \mathrm{HINCH}$, T.D.; DELAMERE, T.A -«Native Festivals as Tourism Attractions: A Community Challenge». Journal of Applied Recreation Research 18, n. ㅇ 2, p 31-42, 1993.

${ }^{21}$ Em geral, vide BOSCH CAMPRUBÍ, R.-Turismo y medio ambiente. Madrid: Ed.Ramón Areces, 2001.

${ }^{22}$ A.VANDERMEY -«Assessing the Importance of Urban Tourism». Tourism Management 5, n.으, 1984, p. 123-35.

${ }^{23}$ UE - "O Papel das Comunidades Europeias da UE em matéria de Turismo". COM(95)97 F.

${ }^{24}$ SESSA, A. -Turismo e política de desenvolvimento, p.123.

${ }^{25}$ VVAA, v.g., PAGÈS FITA, J. -“III.Cidade e políticas culturais": "O Fórum Universal das Culturas: Barcelona 2004", p.83; MARTINELL, A.- “Cultura e cidade: uma aliança para o desenvolvimento. A experiência da Espanha”, p. 93; NETO, P.T.-“Preservação sustentada de sítios históricos: A experiência do Programa Monumenta", p.105; RODRÍGUEZ ALOMÁ, P._“ O Centro Histórico de Havana: Um modelo de gestão pública”, p.117. In Políticas Culturais para o Desenvolvimento: Uma base de dados para a cultura. Brasília: UNESCO, 2003.
} 
conviver, em vez de coexistirem ocupando os novos espaços, então é indispensável integrar adequadamente na herança histórica.

No que concerne, pois, às características do turismo cultural urbano, a riqueza cultural portuguesa e europeia em geral (concretizada na multiplicidade dos monumentos do passado, na valorização das experiências científicas, técnicas e artísticas, acumuladas nos museus, tradicionais ou novos, e na apresentação contínua de criações contemporâneas nas exposições, salões e espetáculos), constitui um dos elementos marcantes da imagem da Europa perante as populações de outros espaços, o que explica o lugar cimeiro que a Europa ocupa nos fluxos turísticos internacionais ${ }^{26-27}$.

Portugal é um território que possui um clima "geográfico" favorável e um "clima cultural", fruto de construções de épocas imperiais e de casario tradicional.

Além de valores imateriais, tem já treze elementos imobiliários excecionais classificados pela UNESCO como património mundial ${ }^{28-29}$. Mas, apesar da riqueza de inúmeros castelos, mosteiros, igrejas, fortes, cidades amuralhadas, não é o património cultural que mais atrai os turistas, faltando ainda políticas de valorização e promoção mais ativas e adequados.

As preocupações de preservação do património materializaram-se, numa primeira fase, na recuperação de edifícios eruditos ou símbolos de marcos históricos, só recentemente apontando para a conservação de edifícios singulares e para a salvaguarda, nas cidades, de conjuntos urbanos.

A imagem da cidade é uma chave fundamental para a atração turística.

Um modelo de atividade turística centrada no valor cultural urbano impele a três tipos principais de intervenção administrativa no e sobre o meio urbano: de conservação loperações de criação, proteção e recuperação) ${ }^{30}$, de reabilitação de locais e edifícios (património militar: fortes, cidadelas, arsenais, muralhas, casernas; património civil: hospitais, castelos, praças, estações e linhas de caminho de ferro; património industrial: manufaturas de tabaco, de têxteis, de munições de armas,

\footnotetext{
${ }^{26}$ Em 1991 (International Tourism 1970-1971, Madrid: WTO, 1992), a Europa recebeu 61\% do total dos turistas a nível internacional e arrecadou 55\% das receitas, com a CEE a 12 países a receber $40 \%$ dos turistas e $50 \%$ das receitas.

${ }^{27}$ Vide «European Travel Monitor» e indicadores estatísticos de ROBERT HOLLIER, 1988, sobre o "turismo urbano na Europa»; COMMISSION DES COMMUNAUTES EUROPEENNES, D.G. XVIII, UNITE TOURISME -«Le Tourism Culturel en Europe». GEATTE, 1993.

${ }^{28}$ Portugal oferece 250 museus.

${ }^{29} \mathrm{http}: / /$ www.portugalturismo.eu/patrimonio.aspx.

30 Nos EUA, desde 1978, o Endangered Properties Fund (DOREL, G -Hommes et Terres du Nord, 1990), em França, os «sectores salvaguardas» (Lei MALRAUX, de 4 Agosto 1962), com proteção também de perímetros delimitados.
} 
de centrais elétricas, etc.; e património portuário: paredões, docas, entrepostos), de afirmação de arte pública e de promoção dos valores e da imagem global da cidade ${ }^{31}{ }^{32}$.

O património-locomotiva do turismo não assenta apenas na mera procura da monumentalidade ou mesmo do estritamente cultural, mas deve levar à invasão da cidade enquanto tal, com tudo o quer ela tem para oferecer.

O património português, com as suas culturas e cidades históricas (ao lado das suas orlas marítimas e temperaturas moderadas) é um fator de promoção do turismo ${ }^{33}$.

Atualmente, o direito já se preocupa com a recuperação dos valores físicos históricos, face à necessidade de salvar todo um patrimônio urbanístico não repetíve ${ }^{34}$, embora os poderes públicos, por razoes de receita tributária, mau gosto dos dirigentes e corrupção generalizada, nem sempre os defendam devidamente. O turismo urbano constitui uma atividade objetivamente complexa e de motivação subjetiva diferenciada e, por vezes, pluralizada, congregando interesses a ter presentes em todas as políticas (estratégias das instituições e operadores particulares) e normações jurídicas.

\section{TURISMO CITADINO E PAPEL DAS POLÍTICAS PÚBLICAS E DO DIREITO}

O direito e as políticas públicas são chamados, cada vez mais, a "enformar" orientações e enquadramentos adequados à promoção do turismo cultural.

O tradicional direito verticalmente turístico, nas habituais preocupações sobre as instâncias de saúde e termais e sobre o sistema hoteleiro ou a restauração, não deixa de continuar a pedir resposta pública a preocupações fundamentais (essencialmente fomentando e controlando a qualidade da oferta de serviços e bens).

Mas a evolução do conceito de interesse público exige vindo a assunção pública de novas tarefas, com normas jurídicas específicas, horizontalmente turísticas, em partes especiais ou mesmo ramos autônomos do direito administrativo, desde logo, os direitos do urbanismo (em geral e regras no regime jurídico da urbanização e edificação, referentes aos estabelecimentos comerciais, recintos

\footnotetext{
${ }^{31}$ Em Portugal, v.g., em Lisboa, os Projectos-Piloto de Valorização Cultural e Turística dos Jardins Históricos: Jardins históricos de Portugal - Projeto-piloto de valorização cultural e turístico (Jardim Botânico da Ajuda, Lisboa / Jardim do Cerco, Mafra). Lisboa: MCT, ISA, CM de Mafra, etc., 1995.

32 Operações-Piloto de Valorização Sociocultural e Turística, v.g., Projeto integrado do Castelo: operação piloto de valorização sociocultural e turística. Lisboa: MCT, CM de Lisboa, 1995.

${ }^{33}$ VANDERMEY, A. -«Assessing the Importance of Urban Tourism». Tourism Management 5, n. 을 1984, p. 123 35.

${ }^{34}$ SALVIA, F. e TERESI, F.-Diritto Urbanístico. 5a edição, Padova: Cedam, 1993, p.188.
} 
de espetáculos e divertimentos públicos e imóveis classificados ou em vias de classificação e respetivas zonas de proteção ${ }^{35}$ ), de defesa do patrimônio e do ambiente urbano.

Se o crescimento das cidades implicou regras disciplinadoras da construção impedindo o desenvolvimento caótico, embora em Portugal se imponha rever certas normas, designadamente interditadoras da edificação não estética ${ }^{36}$, face à sua não efetividade (v.g., al. a) e b), n.으 do art.24.은 da Lei n. $0555 / 99$, de 16.12, referente ao Regime Jurídico da Urbanização e Edificação) ${ }^{37}$.

Em geral, são imprecisas ou letra morta perante as administrações municipais e as jurisdições, que se refugiam na invocação da relatividade e subjetividade da beleza e da estética urbanística, contrariamente ao que se passa noutros países europeus. O que torna Portugal, de fato, neste aspeto, um país terceiromundializado.

A sua revisão é fundamental para a identidade e a atratividade das cidades portuguesas. Noutros domínios não faltam normas estritas e vinculantes, planejamento público ou instrumentos de iniciativa particular e aprovação pública, mas o seu controlo é insuficiente, revelando-se em parte ineficaz.

O "direito a viver num ambiente adequado à saúde e ao bem-estar dos indivíduos" (Diretiva sobre controlo de emissões industriais), a um ambiente de vida humano, sadio e ecologicamente equilibrado" (Constituição) ou o direito de promover a preservação do ambiente e do patrimônio cultural $^{38}$ e a "qualidade de vida" (como expressão de um direito que permita não só estar e sobreviver mas viver em condições sadias ${ }^{39}$ ). Tal como a preocupação de construir novo sem destruir as construções tradicionais ainda sensibiliza pouco os poderes públicos e os tribunais, face aos poderes econômicos e pressões edificadoras. O que só regras menos discricionárias ou com conceitos menos indeterminados e controles mais imperativos e sancionadores pode ultrapassar.

O direito do urbanismo disciplina o fenômeno urbano e edificador.

Mas há normas específicas destinadas a proteger o patrimônio cultural, de modo a evitar a sua descaracterização e a perda de identidade das populações.

Mas o direito do patrimônio cultural não se resume a um "urbanismo" especial.

\footnotetext{
${ }^{35}$ Art. o 37.ํ 1; art.o 38. sobre empreendimentos turísticos e art. 39.ㅇobre autorização prévia de localização.

${ }^{36}$ CONDESSO, F. - «The problem of the aesthetic in modern law of the urbanism: a case of leakage systematic of the right for public administration and courts». In VVAA. Arte Pública e Cidadania. Lisboa: Caleidoscópio, 2010.

${ }^{37}$ A recusa da licença urbanística "pode" assentar num princípio geral de respeito pelo aspeto ou imagem das povoações, conjuntos construídos e da beleza das paisagens, fundado embora em conceitos imprecisos: "afetar negativamente o património arqueológico, histórico, cultural ou paisagístico, natural ou edificado"; "manifestamente afetar o acesso e a utilização de imóveis classificados (...), a estética das povoações, a sua adequada inserção no ambiente urbano (...)".

${ }^{38}$ CASALTA NABAIS, José, Introdução ao direito do património cultural,Cpoimbra:Almedina,2004.

${ }^{39}$ CRP, artigos $52,65,66$. , etc..
} 
Aliás, em Portugal, o aparecimento de legislação de natureza avulsa e esporádica sobre a proteção do patrimônio cultural, é anterior ao moderno direito do urbanismo.

As duas áreas normativas coincidem apenas em parte: patrimônio cultural das cidades, patrimônio arquitetônico urbano e suas zonas de proteção.

Só nestes domínios o direito relativo ao património cultural coincide com o direito do urbanismo, aliás com particularidades.

O patrimônio cultural das cidades é preenchido com um conceito mais restrito do que o de patrimônio em geral ${ }^{40}$. Trata também de um património arquitetónico urbano, mas constituído por monumentos de reconhecido valor histórico e cultural, ou por conjuntos de monumentos classificados. Mas ao objetivo protecionista não basta classificar e preservar edifícios e monumentos individualmente considerados, sendo necessário criar zonas de proteção especial, defender a sua área envolvente.

A proteção do património cultural foi objeto da Convenção Cultural Europeia, de 1954, e da Convenção para a Proteção do Património Arqueológico, de 1969.

No caso do direito da proteção do patrimônio, o conceito de interesse público convive com o conceito de "interesse difuso" ${ }^{141}$ dos cidadãos, possibilitador designadamente de processos cautelares urgentes e da ação popular contra os seus agressores (art.52.ํ, n.ํ3 da Constituição; Código de Processo nos Tribunais Administrativos e Lei n. $\mathbf{0 8 3 / 9 5}$ sobre participação procedimental e defesa de interesses difusos).

Além disso, o direito do ambiente ou do patrimônio cultural podem justificar restrições a outros direitos constitucionalmente protegidos.

O interesse relativo ao patrimônio cultural justifica restrições ou compressões do direito de propriedade e de outros direitos reais. Com a imposição de abertura ao público de certos edifícios, regime restritivo de demolição, obrigação de reparação, limitação do jus aedificandi em sentido amplo e outras restrições, previstas na lei, viabilizadoras de políticas de defesa desse patrimônio ${ }^{42}$.

O turismo é causa e beneficiador da evolução das questões ambientais, ligado ao conceito de turismo sustentável.

\footnotetext{
${ }^{40}$ MARCHAND, F. -«Defesa e Preservação do Património». In Direito do Urbanismo, I.N.A., 1989, p.55.

${ }^{41}$ Traduz um interesse legalmente protegido de uma pluralidade indeterminada ou indeterminável de sujeitos que pode incluir todos os participantes da comunidade geral de referência (v.g., património cultural, ambiente, qualidade de vida, saúde pública, proteção do consumo e domínio público).

${ }^{42}$ Ao ius utendi, fruendi et abutendi seguiu-se uma mera "possibilidade" de construção, com o ius aedificandi dependente de um plano público ou de uma decisão administrativa, um direito de propriedade com limites explícitos e imanentes decorrentes da Constituição, em nome do interesse coletivo, v.g. direitos sociais e culturais, como a defesa do ambiente ou do património.
} 
A União Europeia não tem atribuições específicas no sector do turismo. Mas aponta-lhe medidas instrumentais de outros objetivos, como os de defesa de um ambiente limpo e sadio ${ }^{43}$ (Quinto Programa de Ação Comunitária para o Ambiente), o que depende de normas relacionadas com modos de transporte, gestão da água e dos resíduos e do próprio sector do turismo ${ }^{44}$.

A UE tem avançado em três domínios estreitamente ligados ao turismo: defesa do consumidor, proteção da natureza e património cultural. Face às políticas ambientais unionistas europeias (UE), existe um programa para o ambiente no setor do turismo em geral.

Ele incide na tipologia turística, nos comportamentos e na qualidade dos serviços, também com o turismo cultural e o meio urbano (cidades sustentáveis), liberto de poluição, confusão viária e automóvel particular, a substituir por meios alternativos eficientes.

A preservação e reabilitação do património físico e cultural são fatores de elevação da qualidade de vida das populações, do conjunto da cidade e da motivação crescente dos turistas.

Entre os instrumentos jurídicos e de políticas públicas, destaco várias áreas essências do direito. Desde logo, o regime de área crítica de recuperação e reconversão urbanística (ações expeditas, pelos municípios, em caso de necessidade de intervenção urgente, v.g., expropriação por utilidade pública).

Refiro também o regime de obras do tipo "recria" e coercivas (programas de financiamento especial, regime especial de comparticipação na recuperação de imóveis arrendados, subsídios aos proprietários para parte das obras ou, na sua indisponibilidade, substituindo-se o município, tomando posse administrativa do imóvel e realizando os trabalhos). E, ainda, o regime atributivo do exercício do direito de preferência (transmissões a título oneroso, contrariando processos especulativos, permitindo a aquisição de fogos devolutos e recuperação para realojamentos).

Tudo sem prejuízo de um necessário conjunto de políticas e ações públicas (dinamização económica, animação e promoções culturais, articulação com o sistema urbano envolvente, participação das populações residentes).

E, como área estratégica da intervenção do poder local, com programas e projetos concretos de intervenção integrada (projetos de valorização sociocultural e turística), um regime jurídico enformado por um conceito integrador, articulador e pluridisciplinar, que garanta a requalificação das zonas históricas, reabilitação física do parque habitacional degradado, do património edificado,

\footnotetext{
${ }^{43}$ Plano de Ações Comunitárias a favor do Turismo: COM (91) 97, de 24.4.1991, e o 5ㅇ PACA, etc.

${ }^{44}$ COM ao Conselho, JOCE no 93/C 138/01, de 1.2.93 e COM (95) 624 f, de 10.1.96. Vide, o conceito do turismo sustentável no «Livro Verde» sobre "O papel da União no sector do turismo», que trata dos aspetos ambientais; HUNTER,P. -«Urban Tourism: Perspectives on Susteinability». Journal of Sustainable Tourism, Vol. 4, n. ㅇ 2, Channel View Books, 1996, p.95-111.
} 
reabilitação do espaço público, implementação de equipamentos coletivos, introdução de infraestruturas, disciplina do tráfego, estacionamento e das alterações de uso nos imóveis, com a participação das populações.

Em conclusão, o futuro do "turismo de cidade" joga-se, em grande parte, nas políticas públicas e em várias áreas do direito, a nível europeu e nacional, e no papel das autarquias, a quem cabe um papel proactivo e pedagógico e a tarefa principal da sua promoção, ligada a valores culturais. Em manutenção e permanente criação. E até na "ultrapassagem" da mera visão da dinâmica cultural, assente numa holística multifatorialidade. Jogando o mundo urbano na sua globalidade.

Importa aperfeiçoar essas várias áreas do direito. Com destaque para o direito do patrimônio antigo, cultural, reabilitação urbana, planeamento físico, urbanização e edificação, ambiente urbano, da fiscalidade e incentivos. Além da organização da cidade em termos de inovação e modernidade. Com políticas promotoras de arte pública. E, em geral, eventos desde logo à base de elementos endógenos.

Aceito em agosto 25 de agosto de 2014. 